JAMP: Jurnal Adminitrasi dan Manajemen Pendidikan Volume 1 Nomor 1 Maret 2018, Hal : 7-15

Tersedia Online di http://journal2.um.ac.id/index.php/jamp/ ISSN $x x x x-x x x x$ (online)

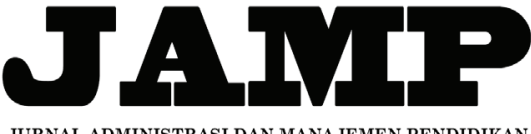

JURNAL ADMINISTRASI DAN MANAJEMEN PENDIDIKAN

\title{
HUBUNGAN KUALITAS KOMPETENSI, BUDAYA ORGANISASI DAN MOTIVASI KERJA DENGAN PELAYANAN PRIMA TENAGA ADMINISTRASI SEKOLAH
}

\author{
Zakiyatul Ummah \\ Achmad Supriyanto \\ Sultoni \\ E-mail : zakiyaumma@gmail.com \\ Universitas Negeri Malang, Jl. Semarang No. 5 Malang 65145

\begin{abstract}
The objective of the research is to know the correlation of competence quality, organizational culture and work motivation with excellent service of TAS. This research is a descriptive correlational research. The study population was TAS and sampling technique using proportional random sampling. Data analysis using descriptive analysis technique and multiple correlation. The result of the research is the correlation between competence quality and excellent service, there is relationship between organizational culture and excellent service, there is work motivation and excellent service relationship, there is significant relation of competence quality, organizational culture and work motivation with excellent service of TAS.
\end{abstract}

Keyword: Quality of competence, organizational culture, work motivation, excellent service.

\begin{abstract}
Abstrak: Tujuan penelitian untuk mengetahui hubungan kualitas kompetensi, budaya organisasi dan motivasi kerja dengan pelayanan primaTAS. Penelitian ini merupakan penelitian yang bersifat deskriptif korelasional. Populasi penelitian ialah TAS dan teknik pengambilan sampel menggunakan proportional random sampling. Analisis data menggunakan teknik analisis deskriptif dan korelasi ganda. Hasil penelitian antara lain terdapat hubungan antara kualitas kompetensi dan pelayanan prima, terdapat hubungan antara budaya organisasi dan pelayanan prima, terdapat hubungan motivasi kerja dan pelayanan prima, terdapat hubungan yang signifikan kualitas kompetensi, budaya organisasi dan motivasi kerja dengan pelayanan prima TAS.
\end{abstract}

Kata kunci: Kualitas kompetensi, budaya organisasi, motivasi kerja, pelayanan prima.

Usaha menyelenggarakan pendidikan dalam rangka memenuhi kebutuhan serta tuntutan zaman tidak serta merta hanya dipengaruhi oleh kontribusi guru. Sebab, selain proses pembelajaran dalam lembaga pendidikan sendiri juga masih banyak masalah kompleks lain yang harus ditangani seperti halnya persoalan anggaran dan sistem pendidikan yang kurang mendukung untuk peningkatan mutu pendidikan.

Pemenuhan standar Tenaga Administrasi Sekolah/Madrasah (TAS/M) mampu meningkatkan kualitas kinerja dan pemberian layanan untuk seluruh pengguna jasa pendidikan. Sesuai dalam Permendiknas Nomor 24 Tahun 2008 tentang standar TAS/M, dimensi kompetensi yang wajib dimiliki oleh Kepala TAS ialah kompetensi kepribadian, kompetensi sosial, kompetensi teknis, dan kompetensi manajerial. Dimensi kompetensi yang dimiliki oleh pelaksana urusan dan petugas layanan khusus ialah kompetensi kepribadian, kompetensi sosial, dan kompetensi teknis. 
Kinerja TAS tergolong dalam kategori baik jika dalam pemberian layanan telah dapat memenuhi standar dalam pelayanan prima bagi pengguna jasa pendidikan. Menurut Zulkarnain dan Sumarsono (2011) pelayanan diartikan sebagai sebuah tindakan yang diberikan satu pihak terhadap pihak lain tanpa menghasilkan sebuah kepemilikan sesuatu bagi salah satu pihak. Lima komponen dalam pelayanan yaitu; (1) reliabilitas, (2) daya tanggap, (3) jaminan, (4) empati, (5) bukti fisik.

Kompetensi berdasarkan Badan Kepegawaian Negara Nomor 46A Tahun 2003 bahwa kompetensi merupakan pengetahuan serta keterampilan seseorang yang terkait dengan tugas jabatannya yang mendukung dalam plaksanaan tugas yang dibebankan secara profesional, efektif dan efisien. Mantja (2007) menjelaskan bahwa kompetensi ialah kemampuan dalam diri seseorang untuk mengerjakan sesuatu yang dapat diperoleh dari sebuah pelatihan maupun pendidikan. Soetjipto (2015) menyatakan bahwa kompetensi ialah kemampuan seseorang sehingga memungkinkan dirinya mendapatkan kepercayaan untuk melaksanakan pekerjaan yang diberikan. Seorang TAS dapat dianggap mampu menjalankan pekerjaannya apabila telah memenuhi standar yang disyaratkan. Dengan adanya standar kompetensi maka diharapkan seorang TAS memiliki kesempatan untuk mengembangkan kemampuan yang dimilikinya secara kontinyu. Hal tersebut bertujuan untuk mengimbangi pelayanan yang diberikan oleh komponen lainnya pada lembaga dalam melayani proses pembelajaran.

Budaya organisasi dalam lembaga pendidikan memberikan pengaruh terhadap persepsi para pegawai/staf yang berakibat pada kinerja pegawai dalam melayani pelanggan pendidikan. Rivai (2004) menjelaskan budaya organisasi berkaitan dengan sudut pandang para karyawan mengenai budaya yang terbentuk dalam organisasi tersebut. Kreitner dan Kinicki (2005) menjelaskan budaya organisasi merupakan sebuah anggapan yang dimiliki, dirasakan serta dianut oleh semua anggota dalam sebuah organisasi yang mempengaruhi perasaan maupun perilaku anggota dalam menjalin hubungan dengan lingkungan sekitarnya. Jadi, dapat dikatakan bahwa perlu adanya sebuah persepsi yang sama pada setiap diri pegawai masing-masing. Tiga tipe umum budaya organisasi dijabarkan Kreitner dan Kinicki (dalam Ardana, dkk, 2013:169) antara lain: (1) budaya konstruktif, (2) budaya pasif-defensif, (3) budaya agresif-defensif. Budaya organisasi sebagai ciri dan karakter dalam membangun dan membentuk suatu organisasi memiliki fungsi antara lain seperti yang dijelaskan Sutrisno (2010) yakni untuk menyatukan seluruh anggota dalam mencapai tujuan-tujuan organisasi yang meliputi ketentuan serta nilai-nilai yang harus dijalankan para karyawan.

Motivasi dikatakan sebagai sebuah bagian penting dalam sebuah kegiatan yang berlangsung, tanpa motivasi maka tidak ada kegiatan yang mampu berjalan dengan lancar dan maksimal. Pegawai dengan sendirinya akan menyelesaikan pekerjaannya secara maksimal jika mempunyai tingkat motivasi yang tinggi. Motivasi kerja berarti dorongan yang berasal dari dalam diri individu untuk menjalankan tugas dan pekerjaannya. Marliani (2015) mendefinisikan motivasi kerja sebagai semangat maupun dorongan dari dalam diri individu untuk melaksanakan sebuah pekerjaan karena mereka memiliki keinginan untuk melakukannya serta bertujuan untuk mencapai tujuan yang diinginkan. Waluyo (2013) mengungkapkan bahwa motivasi kerja ialah sebuah dorongan atau semangat untuk melaksanakan pekerjaan. Motivasi menjadi sebuah hal yang sangat penting, beberapa alasan pentingnya sebuah motivasi, antara lain: a) motivasi merupakan suatu yang penting (important subject); b) motivasi ialah sesuatu yang sulit (puzzling subject). Faktor-faktor penyebab tingginya motivasi kerja menurut Ardana, dkk. (2013:31-32) antara lain: (1) karakteristik individu, (2) faktor dalam pekerjaan, (3) faktor lingkungan pekerjaan.

Hasil penelitian Zuamah (2007) menunjukkan konsep pelayanan prima akan mampu berjalan dengan baik apabila dalam organisasi memiliki kompetensi yang handal dari para anggota organisasi, kompetensi yang ada digunakan untuk menunjang pelayanan bagi pelanggan. Hasil penelitian Ramdani (2014) menyatakan bahwa layanan yang berkualitas sebuah organisasi berasal dari budaya organisasi yang menetapkan pelayanan prima sebagai ciri maupun karakter dari sebuah organisasi. Selain kualitas kompetensi dan budaya organisasi, penelitian dari Mukaromah (2016) menunjukkan motivasi kerja memiliki pengaruh secara signifikan dengan mutu pelayanan karyawan. Berdasarkan beberapa temuan hasil penelitian dari peneliti terdahulu maka dapat diambil sebuah kesimpulan bahwa adanya hubungan kualitas kompetensi, budaya organisasi dan motivasi kerja dengan pelayanan prima TAS. 
Berdasarkan kajian tersebut maka hipotesis yang disusun terkait dengan penelitian ini sebagai berikut: (1) terdapat hubungan antara kualitas kompetensi dan pelayanan prima TAS, (2) terdapat hubungan antara budaya organisasi dan pelayanan prima TAS, (3) terdapat hubungan antara motivasi kerja dan pelayanan prima TAS, (4) terdapat hubungan kualitas komptensi, budaya organisasi dan motivasi kerja dengan pelayanan TAS.

\section{METODE}

Penelitian ini menggunakan pendekatan kuantitatif deskriptif. Penelitian ini bersifat deskriptif korelasional sebab bertujuan untuk mengetahui ada atau tidaknya hubungan antara variabel kualitas kompetensi (X1), budaya organisasi (X2), dan motivasi kerja (X3) dengan pelayanan prima (Y). Populasi dalam penelitian ini yaitu TAS SMA Negeri di Kabupaten Lamongan dengan jumlah 174 dan diperoleh 121 sampel. Teknik pengambilan serta penentuan sampel yang digunakan dalam penelitian ini menggunakan proportional random sampling dan simple random sampling. Penelitian ini menggunakan data kuantitatif jenis data interval. Instrumen penelitian ini menggunakan kuesioner (questionnaire) untuk mengukur fakta atau data bersifat fisik. Kuesioner yang digunakan berupa model Skala Likert, dengan menggunakan alternatif jawaban antara lain: (1) SS/SL, (2) S/SR, (3) TS/JR, (4) STS/TP. Terdapat empat tahap dalam pengumpulan data, yaitu: (1) tahap pengumpulan, (2) tahap pelaksanaan, (3) tahap pengolahan data, (4) tahap pelaporan. Analisis data dalam penelitian antara lain: (1) uji prasyarat analisis, yang meliputi uji normalitas dan uji linearitas, (2) analisis deskriptif, yaitu dengan menentukan panjang kelas interval, menentukan persentase, mencari mean, (3) analisis korelasi product moment pearson, (4) analisis korelasi ganda.

\section{HASIL}

Hasil yang diperoleh dari penelitian ini dikelompokkan ke dalam dua bagian, yaitu deskripsi data dan pengujian hipotesis. Hasil analisis deskriptif kondisi dari kualitas kompetensi, budaya organisasi dan motivasi kerja dengan pelayanan prima TAS dapat dilihat pada Tabel 1, 2, 3, dan 4. Deskripsi variabel kualitas kompetensi TAS (sub variabel kompetensi kepribadian, kompetensi sosial dan kompetensi teknis) disajikan pada Tabel 1.

Tabel 1 Kualifikasi dan Interval Nilai (X1)

\begin{tabular}{|c|c|c|c|c|c|c|}
\hline No & $\begin{array}{c}\text { Alternatif } \\
\text { Jawaban }\end{array}$ & Kode & Interval & Kategori & Frekuensi & Persentase \\
\hline 1. & SS/SL & 4 & $160-196$ & Sangat Tinggi & 81 & 66.9 \\
\hline 2. & S/SR & 3 & 123-159 & Tinggi & 40 & 33.1 \\
\hline 3. & TS/JR & 2 & $86-122$ & Rendah & $\mathbf{0}$ & $\mathbf{0}$ \\
\hline 4. & STS/TP & 1 & $49-85$ & Sangat Rendah & $\mathbf{0}$ & $\mathbf{0}$ \\
\hline \multicolumn{5}{|c|}{ TOTAL } & 121 & 100.0 \\
\hline
\end{tabular}

Sumber: Data Diolah Peneliti (2017)

Berdasarkan Tabel 1 dapat dilihat bahwa dari 121 responden, 81 TAS $(66,9 \%)$ responden menyatakan bahwa kualitas kompetensi yang dimiliki TAS dalam pemberian pelayanan prima berada dalam kualifikasi sangat tinggi, 40 TAS $(44,1 \%)$ responden menyatakan bahwa kualitas kompetensi yang dimiliki TAS dalam pemberian pelayanan prima berada dalam kualifikasi tinggi, dan tidak ada responden yang menyatakan rendah dan sangat rendah terkait kualitas kompetensi yang dimiliki TAS dalam pemberian pelayanan prima. Nilai mean kualitas kompetensi yaitu 169,26 terdapat pada interval 160-196 yang tergolong dalam kategori sangat tinggi. Untuk deskripsinya disajikan dalam bentuk Pie pada Gambar 1. 


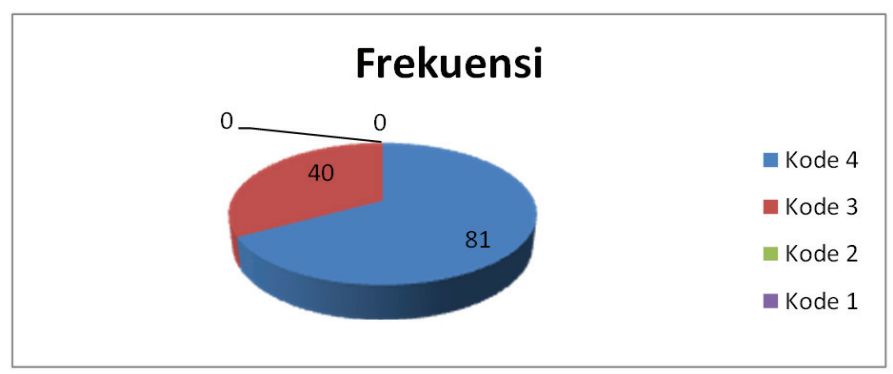

Gambar 1 Kualifikasi dan Interval Nilai (X1)

Variabel budaya organisasi (X2) dijabarkan dalam bentuk tabel dan gambar Pie. Deskripsi variabel budaya organisasi (sub variabel budaya konstruktif, budaya pasif-defensif, budaya agresif-defensif) disajikan dalam Tabel 2.

Tabel 2 Kualifikasi dan Interval Nilai (X2)

\begin{tabular}{|c|c|c|c|c|c|c|}
\hline No & $\begin{array}{c}\text { Alternatif } \\
\text { Jawaban }\end{array}$ & Kode & Interval & Kategori & Frekuensi & Persentase \\
\hline 1. & $\mathbf{S S} / \mathbf{S L}$ & 4 & $121-148$ & Sangat Tinggi & 70 & 57.9 \\
\hline 2. & S/SR & 3 & $93-120$ & Tinggi & 50 & 41.3 \\
\hline 3. & TS/JR & 2 & 65-92 & Rendah & 1 & .8 \\
\hline 4. & STS/TP & 1 & $37-64$ & Sangat Rendah & $\mathbf{0}$ & $\mathbf{0}$ \\
\hline \multicolumn{5}{|c|}{ TOTAL } & 121 & 100.0 \\
\hline
\end{tabular}

Sumber: Data Diolah Peneliti (2017)

Berdasarkan Tabel 2 menunjukkan bahwa dari 121 responden, 70 TAS (57,9\%) responden menyatakan bahwa budaya organisasi yang dimiliki TAS dalam pemberian pelayanan prima berada dalam kualifikasi sangat tinggi, 50 TAS $(41,3 \%)$ responden menyatakan bahwa budaya organisasi yang dimiliki TAS dalam pemberian pelayanan prima berada dalam kualifikasi tinggi, 1 TAS $(0,8 \%)$ responden menyatakan bahwa budaya organisasi yang dimiliki TAS dalam pemberian pelayanan prima berada dalam kualifikasi rendah, dan tidak ada responden yang menyatakan sangat rendah terkait budaya organisasi yang dimiliki TAS dalam pemberian pelayanan prima. Nilai mean budaya organisasi yaitu 122,35 terletak pada interval 121-148 yang tergolong dalam kategori sangat tinggi. Untuk deskripsinya disajikan dalam bentuk Pie pada Gambar 2

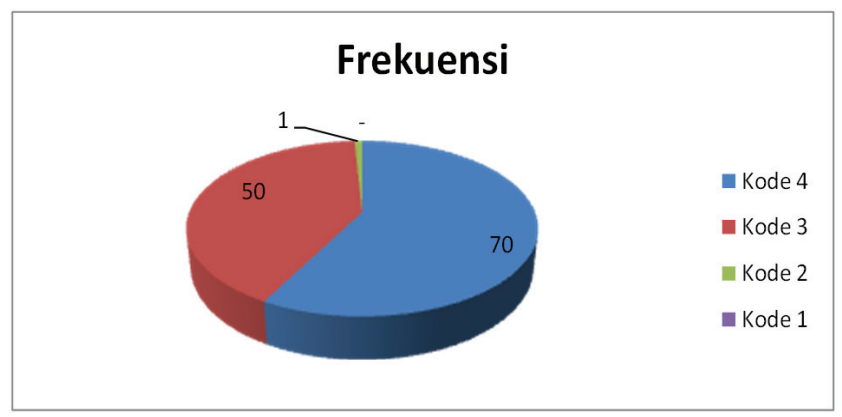

Gambar 2 Kualifikasi dan Interval Nilai (X2)

Variabel motivasi kerja disajikan kedalam bentuk tabel dan gambar Pie. Deskripsi variabel motivasi kerja (sub variabel karakteristik individu, faktor dalam pekerjaan, faktor lingkungan pekerjaan) dapat dilihat pada Tabel 3 . 
Tabel 3 Kualifikasi dan Interval Nilai (X3)

\begin{tabular}{lcccccc}
\hline No & $\begin{array}{c}\text { Alternatif } \\
\text { Jawaban }\end{array}$ & Kode & Interval & Kategori & Frekuensi & Persentase \\
\hline 1. & SS/SL & 4 & $\mathbf{1 8 0 - 2 2 1}$ & Sangat Tinggi & 73 & 60.3 \\
2. & S/SR & 3 & $138-179$ & Tinggi & 46 & 38.0 \\
3. & TS/JR & 2 & $96-137$ & Rendah & 2 & 1.7 \\
4. & STS/TP & 1 & $54-95$ & Sangat Rendah & 0 & 0 \\
\hline & TOTAL & 121 & 100.0
\end{tabular}

Sumber: Data Diolah Peneliti (2017)

Berdasarkan Tabel 3 menunjukkan bahwa dari 121 responden, 73 TAS $(60,3 \%)$ responden menyatakan bahwa motivasi kerja yang dimiliki TAS dalam pemberian pelayanan prima berada dalam kualifikasi sangat tinggi, 46 TAS $(38,0 \%)$ responden menyatakan bahwa motivasi kerja yang dimiliki TAS dalam pemberian pelayanan prima berada dalam kualifikasi tinggi, 2 TAS $(1,7 \%)$ responden menyatakan bahwa motivasi kerja yang dimiliki TAS dalam pemberian pelayanan prima berada dalam kualifikasi rendah, dan tidak ada responden yang menyatakan sangat rendah terkait motivasi kerja yang dimiliki TAS dalam pemberian pelayanan prima. Nilai mean motivasi kerja yaitu 183,93 terletak pada interval 180-221 yang tergolong dalam kategori sangat tinggi. Untuk deskripsinya disajikan dalam bentuk Pie pada Gambar 3.

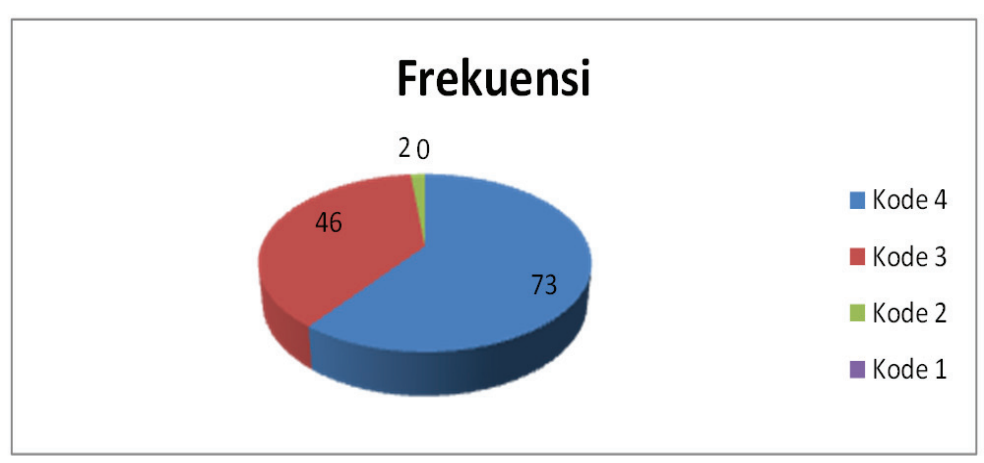

Gambar 3 Kualifikasi dan Interval Nilai (X3)

Variabel pelayanan prima (Y) disajikan dalam bentuk tabel dan gambar Pie. Deskripsi variabel pelayanan prima (sub variabel bukti fisik, keandalan, daya tanggap, jaminan, empati) dijabarkan pada Tabel 4.

Tabel 4 Kualifikasi dan Interval Nilai (Y)

\begin{tabular}{|c|c|c|c|c|c|c|}
\hline No & $\begin{array}{c}\text { Alternatif } \\
\text { Jawaban }\end{array}$ & Kode & Interval & Kategori & Frekuensi & Persentase \\
\hline 1. & SS/SL & 4 & $99-121$ & Sangat Tinggi & 91 & 75.2 \\
\hline 2. & S/SR & 3 & $76-98$ & Tinggi & 30 & 24.8 \\
\hline 3. & TS/JR & 2 & $53-75$ & Rendah & $\mathbf{0}$ & $\mathbf{0}$ \\
\hline 4. & STS/TP & 1 & $30-52$ & Sangat Rendah & $\mathbf{0}$ & $\mathbf{0}$ \\
\hline \multicolumn{5}{|c|}{ TOTAL } & 121 & 100.0 \\
\hline
\end{tabular}

Sumber: Data Diolah Peneliti (2017)

Berdasarkan Tabel 4 menunjukkan bahwa dari 121 responden, 91 TAS (75,2\%) responden menyatakan bahwa pelayanan prima yang diberikan TAS berada dalam kualifikasi sangat tinggi, 30 TAS $(24,8 \%)$ responden menyatakan bahwa pelayanan prima yang diberikan TAS berada dalam kualifikasi tinggi, dan tidak ada responden yang menyatakan rendah dan sangat rendah terkait pelayanan prima yang 
diberikan TAS. nilai mean pelayanan prima yaitu 106,17 berada pada interval 99-121 yang tergolong dalam kategori sangat tinggi. Untuk deskripsinya disajikan dalam bentuk Pie pada Gambar 4.

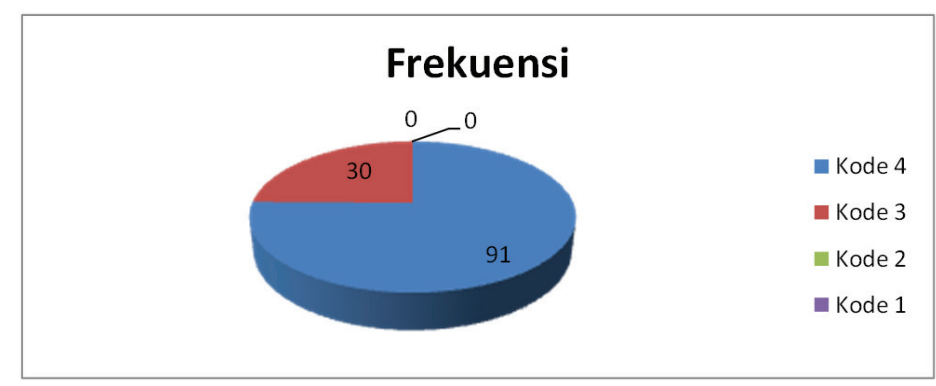

Gambar 4 Kualifikasi dan Interval Nilai (Y)

\section{Pengujian Hipotesis 1}

Hipotesis yang diuji secara statistik dalam penelitian ini yaitu "terdapat hubungan yang signifikan kualitas kompetensi dan pelayanan prima TAS". Hasil dari analisis korelasi yang dilakukan menunjukkan Pada T X1 (total variabel kualitas kompetensi) diperoleh nilai signifikansi 2-tailed sebesar $0,000<$ 0,05 . Hal tersebut berarti bahwa $\mathrm{H} 1$ diterima sehingga terdapat hubungan yang signifikan antara kualitas kompetensi dan pelayanan prima TAS SMA Negeri di Kabupaten Lamongan.

\section{Pengujian Hipotesis 2}

Hipotesis yang diuji secara statistik dalam penelitian ini yaitu "terdapat hubungan yang signifikan budaya organisasi dan pelayanan prima TAS". Analisis korelasi yang dilakukan menunjukkan hasil Pada T_X2 (total variabel budaya organisasi) diperoleh nilai signifikansi 2-tailed sebesar $0,000<0,05$. Sehingga hal tersebut berarti bahwa $\mathrm{H} 1$ diterima dan terdapat hubungan yang signifikan antara budaya organisasi dan pelayanan prima TAS SMA Negeri di Kabupaten Lamongan.

\section{Pengujian Hipotesis 3}

Hipotesis yang diuji secara statistik dalam penelitian ini yaitu "terdapat hubungan yang signifikan motivasi kerja dan pelayanan prima TAS". Hasil analisis korelasi menunjukkan Pada T_X3 (total variabel motivasi kerja) diperoleh nilai signifikansi 2-tailed sebesar $0,000<0,05$. Sehingga dapat disimpulkan bahwa $\mathrm{H} 1$ diterima dan diartikan terdapat hubungan yang signifikan antara motivasi kerja dan pelayanan prima TAS SMA Negeri di Kabupaten Lamongan.

\section{Pengujian Hipotesis 4}

Hipotesis yang diuji secara statistik dalam penelitian yaitu "terdapat hubungan yang signifikan kualitas kompetensi, budaya organisasi dan motivasi kerja dengan pelayanan prima TAS". Analisis korelasi yang dilakukan menunjukkan hasil nilai Fhitung sebesar 39,381 dengan nilai signifikansi 0,000. Nilai Fhitung (39.381) $>$ Ftabel $(0,1786)$ dan nilai signifikansi lebih kecil dari nilai probabilitas 0,05 atau nilai $0,000<0,05$. Hal tersebut dapat diartikan pula bahwa $\mathrm{H} 1$ diterima dan $\mathrm{H} 0$ ditolak, yang berarti ada hubungan yang positif pada variabel kualitas kompetensi, budaya organisasi dan motivasi kerja dengan pelayanan prima TAS SMA Negeri di Kabupaten Lamongan.

\section{PEMBAHASAN}

\section{Hubungan antara Kualitas Kompetensi dan Pelayanan Prima TAS}

Berdasarkan pengujian menggunakan Product Moment Pearson menunjukkan hasil yaitu adanya hubungan yang positif dan signifikan antara kualitas kompetensi (X1) dan pelayanan prima (Y). Hasil dari penelitian ini sejalan dengan penelitian yang dilakukan oleh Hanitha (2013) memberikan hasil yang mengatakan bahwa pegawai memiliki kompetensi yang baik dilihat dari penilaian melalui indikator pengetahuan, keterampilan dan sikap yang dimiliki dalam pemberian pelayanan kepada masyarakat. Hasil Riset Gunadi, dkk. (2016) menunjukkan bahwa berdasarkan analisis jalur kompetensi pegawai 
terdapat pengaruh terhadap kualitas pelayanan.

Penelitian ini menunjukkan sebagian besar TAS memiliki kualitas kompetensi yang sangat tinggi serta pelayanan prima yang juga sangat tinggi. Jika kualitas kompetensi yang dimiliki TAS sangat tinggi, maka pemberian pelayanan prima oleh TAS juga sangat tinggi. Kualitas kompetensi yang sangat tinggi dapat meningkatkan kualitas seorang individu dalam melakukan pekerjaannya yang dapat ditunjukkan melalui pemberian pelayanan prima.

\section{Hubungan antara Budaya Organisasi dan Pelayanan Prima TAS}

Hasil pengujian Product Moment Pearson menunjukkan bahwa terdapat hubungan secara signifikan antara budaya organisasi (X2) dan pelayanan prima (Y). Hasil dari penelitian ini senada dengan hasil penelitian yang dilakukan Purba (2015) dan menunjukkan bahwa terdapat pengaruh antara budaya organisasi dengan kualitas pelayanan publik dan jika dilihat dari hasil perhitungan koefisien determinan menunjukkan budaya organisasi pegawai memberikan pengaruh sebesar 57,90\% terhadap kualitas pelayanan. Hasil riset lain ialah penelitian Agusriadi (2016) menunjukkan terlihat adanya pengaruh yang signifikan antara variabel budaya organiasasi dengan variabel kualitas pelayanan bagi pegawai.

Hasil dari penelitian ini menunjukkan bahwa sebagian besar TAS memiliki budaya organisasi dan pelayanan prima yang sangat tinggi. Hal ini berarti bahwa tingkat kondusivitas budaya organisasi mampu meningkatkan pelayanan prima yang diberikan TAS. Pelayanan prima dapat diwujudkan apabila dalam sebuah organisasi menjadikan pelayanan prima sebagai budaya yang harus dijalankan dan dianut bersama.

\section{Hubungan antara Motivasi Kerja dan Pelayanan Prima TAS}

Hasil pengujian yang dilakukan dengan bantuan Product Moment Pearson menunjukkan bahwa terdapat hubungan secara signifikan antara motivasi kerja (X3) dan pelayanan prima (Y). Hasil penelitian ini sejalan dengan penelitian yang dilakukan Mukaromah (2016) menunjukkan bahwa terdapat pengaruh yang signifikan antara motivasi kerja dengan mutu pelayanan karyawan. Hal ini berarti bahwa jika semakin tinggi tingkat motivasi kerja yang dimiliki karyawan maka semakin tinggi pula mutu pelayanan yang diberikan. Tamuan dari peneliti terdahulu yang sesuai ialah penelitian oleh Muttaqin, dkk. (2013:251) yang menunjukkan bahwa adanya pengaruh motivasi kerja internal lebih besar daripada motivasi kerja eksternal dari diri pegawai terhadap pelayanan publik pada sebuah organisasi.

Hasil penelitian ini menunjukkan sebagian besar TAS mempunyai motivasi kerja yang sangat tinggi serta pelayanan prima yang juga sangat tinggi. Berdasarkan hal tersebut dapat diartikan bahwa motivasi kerja yang dimiliki TAS mampu meningkatkan pelayanan prima yang diberikan. Semakin tinggi dorongan dalam diri seorang pegawai dalam menjalankan pekerjaannya maka semakin tinggi pula pelayanan prima yang diberikan.

\section{Hubungan Kualitas Kompetensi, Budaya Organisasi dan Motivasi Kerja dengan Pelayanan Prima TAS}

Hubungan kualitas kompetensi, budaya organisasi dan motivasi kerja dengan pelayanan prima TAS dapat dilihat pada hasil penelitian yang menunjukkan total X diperoleh nilai signifikansi 2-tailed sebesar $0,000<0,05$ yang berarti $\mathrm{H} 0$ ditolak dan $\mathrm{H} 1$ diterima maka dapat diartikan pula ada hubungan positif antara kualitas kompetensi, budaya organisasi dan motivasi kerja dengan pelayanan prima TAS.

Hasil penelitian ini sejalan dengan hasil penelitian yang dilakukan oleh Gunadi, dkk. (2016) bahwa kompetensi pegawai memiliki pengaruh terhadap kualitas pelayanan. Sedangkan pada budaya organisasi berdasarkan penelitian Purba (2015) berpengaruh sebanyak 57, 90\% terhadap kualitas pelayanan. Hubungan motivasi kerja berdasarkan hasil penelitian dari Mukaromah (2016:272) motivasi kerja berpengaruh signifikan dengan mutu pelayanan.

Keberhasilan seorang TAS dalam pemberian pelayanan prima tidak hanya dipengaruhi oleh adanya kualitas kompetensi dan budaya organisasi pada lembaga. Peranan tenaga kependidikan dalam memajukan kualitas serta akuntabilitas terhadap masyarakat tidak dapat diabaikan. Kepuasan pengguna jasa pendidikan harus diperhatikan oleh TAS selaku pelayan administrasi dalam lembaga pendidikan. 
Hal tersebut dapat dicapai apabila TAS memiliki kualitas kompetensi yang tinggi dan memenuhi standar yang disyaratkan oleh pemerintah. Disamping itu kebiasaan-kebiasaan selama bekerja juga harus diperhatikan agar pegawai memiliki cara pandang yang sama. Budaya organisasi maupun kebiasaankebiasaan dalam organisasi merupakan cara untuk merekatkan hubungan sosial antar pegawai. Pegawai juga harus memiliki motivasi kerja yang tergolong tinggi sebagai dorongan dalam bekerja. Dengan adanya ketiga hal tersebut maka TAS mampu memberikan pelayanan prima kepada pelanggan.

\section{KESIMPULAN DAN SARAN}

\section{Kesimpulan}

Berdasarkan hasil penelitian dan hasil pembahasan maka dapat ditarik sebuah kesimpulan sebagai berikut: (1) terdapat hubungan yang signifikan antara kualitas kompetensi dan pelayanan prima TAS, (2) terdapat hubungan yang signifikan antara budaya organisasi dan pelayanan prima TAS, (3) terdapat hubungan yang signifikan antara motivasi kerja dan pelayanan prima TAS, (4) terdapat hubungan yang signifikan antara kualitas kompetensi, budaya organisasi dan motivasi kerja dengan pelayanan prima TAS.

\section{Saran}

Penelitian ini memberikan saran kepada: (1) kepala sekolah, jika ingin meningkatkan pelayanan prima TAS maka diharapkan memperhatikan dan melakukan peningkatan kualitas kompetensi, budaya organisasi dan motivasi kerja TAS. Kepala sekolah juga harus lebih fokus serta memperhatikan budaya organisasi dalam lembaganya. Selain itu kepala sekolah juga disarankan agar selalu meningkatkan motivasi kerja dalam diri TAS, (2) TAS, diharapkan terus meningkatkan kualitas kompetensi khususnya kompetensi kepribadian dan kompetensi sosial agar dapat mengimbangi kompetensi teknis yang dimiliki. Agar dapat bekerja maksimal maka TAS diharapkan turut serta dalam membentuk budaya organisasi yang positif. TAS juga diharapkan agar meningkatkan motivasi kerja melalui faktor dalam pekerjaan dan faktor lingkungan pekerjaan serta tetap mempertahankan karakteristik individu. Agar terciptanya pelayanan prima maka TAS juga diharapkan meningkatkan daya tanggap, keandalan, jaminan dan empati serta mempertahankan bukti fisik dalam pelayanan prima, (3) ketua jurusan administrasi pendidikan, diharapkan mencermati kembali silabus matakuliah manajemen perkantoran agar memasukkan kualitas kompetensi, budaya organisasi dan motivasi kerja dengan pelayanan ke dalam silabus. Agar selanjutnya dijadikan sebagai bahan perkuliahan mahasiswa administrasi pendidikan sehingga mahasiswa dapat memperdalam ilmu pengetahuan yang terkait dengan pelayanan prima, (4) bagi peneliti selanjutnya, disarankan untuk menggunakan variabel lain seperti kepuasan siswa terhadap pelayanan yang diberikan oleh TAS. Peneliti selanjutnya juga dapat menggunakan pendekatan kualitatif sehingga dapat memperoleh data secara lebih luas dan mendalam.

\section{DAFTAR RUJUKAN}

Agusriadi. 2016. Pengaruh Budaya Organisasi terhadap Kualitas Pelayanan Pegawai pada Kantor Kecamatan Tanjungpinang Timur Kota Tanjungpinang, (Online), (http://jurnal.umrah.ac.id/wp-content/uploads/gravity forms/1-ec61c9cb232a03a96d0947c6478e525e/2016/08/JURNAL-AGUSRIADI-Copy.pdf), diakses 12 Februari 2017.

Ardana, K. \& Mujiati, N. W. \& Sriathi, A. A. A. 2013. Perilaku Keorganisasian Edisi 2. Yogyakarta: Graha Ilmu.

Gunadi. \& Irawan, I. \& Ratnasari, S.L. \& Wibisono, C. 2016. Kualitas Layanan sebagai Variabel Interventing antara Kompetensi Pegawai dan Budaya Kerja terhadap Kepuasan Mitra di Pelayanan Terpadu Satu Pintu Badan Pengusahaan Kawasan Perdagangan Bebas dan Pelabuhan Bebas Batam, (Online), (http://p2m. polibatam.ac.id/wp-content/uploads/2016/02/7.-Jurnal-Adi.pdf), diakses 12 Februari 2017.

Hanitha, Y. 2013. Pengaruh Kompetensi Pegawai terhadap Kualitas Pelayanan di Kantor Camat Sajad Kabupaten Sambas, (Online), Vol. 1 No. 1, (https://www.google.co.id/ 
Keputusan Kepala Badan Kepegawaian Negara Nomor 46 A Tahun 2003 tentang Pedoman Penyusunan Standar Kompetensi Jabatan Struktural Pegawai Negeri Sipil, (Online), (https://mashanafi.files.wordpress. com/2011/09/keputusan-kepala-bkn-nomor-46a-tahun-2003.pdf), diakses 02 Februari 2017.

Kreitner, R \& Kinicki, A. 2005. Perilaku Organisasi: Organizational Behavior. Jakarta: Penerbit Salemba Empat. Mantja, W. 2007. Profesionalisasi Tenaga Kependidikan: Manajemen Pendidikan dan Supervisi Pengajaran. Malang: Elang Mas.

Marliani, R. 2015. Psikologi Industri dan Organisasi. Bandung: CV Pustaka Setia.

Mukaromah. 2016. Pengaruh Motivasi Kerja dan Kemampuan Kerja terhadap Mutu Pelayanan Karyawan Bank Rakyat Indonesia Balikpapan. Jurnal Psikologi, (Online), Vol 4, No 2, (http:/ejournal.psikologi.fisip-unmul. ac.id/site/wp-content/uploads/2016/08/Jurnal\%20Mukaromah\%20-\%20ONLINE\%20(08-15-16-05-11-42). pdf), diakses 12 Februari 2017.

Muttaqin, N. I. \& Djumadi. \& Noor, M. 2013. Pengaruh Motivasi Kerja terhadap Pelayanan Publik di Kantor Camat Tenggarong Kabupaten Kutai Kertanegara. Jurnal Administrasi Transformasi, (Online), Vol. 1 No. 1, (http://ar.mian.fisip-unmul.ac.id/site/wp-content/uploads/2013/06/02_format_artikel_ejournal_mulai_hlm_ genap\%20oks\%20(06-06-13-02-21-44).pdf), diakses 16 Februari $201 \overline{7}$.

Peraturan Menteri Pendidikan Nasional Republik Indonesia Nomor 24 Tahun 2008 tentang Standar Tenaga Administrasi Sekolah/Madrasah, (Online), (https://docs.google.com/file/ d/0B2qLrZkRe9a2SE1qTkpaNWhnQTA/edit), diakses 02 Februari 2017.

Purba, A. C. 2015. Pengaruh Budaya Organisasi terhadap Kualitas Pelayanan Publik (Studi pada Kantor Unit Pelayanan Terpadu (UPT) Samsat Medan Selatan, (Online), (http://id.123dok.com/document/wye8lry7pengaruh-budaya-organisasi-terhadap-kualitas-pelayanan-publik-studi-pada-kantor-unit-pelayanan-terpaduupt-samsat-medan-selatan.html), diakses 16 Februari 2017.

Ramdani, D. 2014. Budaya Kualitas sebagai Dasar Layanan Prima, (Online), (http://www.bppk.kemenkeu. go.id/publikasi/artikel/167-artikel-pajak/12687-budaya-kualitas-sebagai-dasar-layanan-prima), diakses 12 Februari 2017.

Rivai, B. 2004. Kepemimpinan dan Perilaku Organisasi. Jakarta: PT. RajaGrafindo Persada.

Sutrisno, E. 2010. Budaya Organisasi. Jakarta: Prenadamedia Group.

Soetjipto, H. 2015. Mengembangkan Koperasi: Penerapan Prinsip-prinsip manajemen, Strategi Bisnin yang Tepat, Identifikasi Potensi, Mengenali Permasalahan, dan Merumuskan Strategi Pengelolaan sesuai Prinsip Dasar Koperasi. Yogyakarta: Cahaya Atma Pustaka.

Waluyo, M. 2013. Psikologi Industri. Jakarta Barat: Akademia Permata.

Zuamah. 2007. Analisis Pengaruh Kompetensi Teknis, Kompetensi Sosial, dan Kualitas Interaksi terhadap Kualitas Layanan dalam Meningkatkan Citra Perusahaan dan Kepuasan Konsumen, (Online), (http://eprints.undip. ac.id/17912/1/ZUAMAH.pdf), diakses 12 Februari 2017.

Zulkarnain, W \& Sumarsono, R. B. 2011. Manajemen Perkantoran Profesional. Malang: Gunung Samudra 